\title{
Book Review: Evolution Driven by Organismal Behavior: A Unifying View of Life, Function, Form, Mismatches and Trends
}

\author{
Anne M. Burrows * \\ Department of Physical Therapy, Duquesne University, Pittsburgh, PA, United States
}

Keywords: once, evolution, behavior, animal, biology science, history and philosophy of science

\author{
A Book Review on \\ Evolution Driven by Organismal Behavior: A Unifying View of Life, Function, Form, \\ Mismatches and Trends
}

Rui Diogo, (New York, NY: Springer), 2017, 252 pages, ISBN: 978-3-319-47581-3.

\section{OPEN ACCESS}

Edited and reviewed by: Matjaz Kuntner,

Scientific Research Centre of the Slovenian Academy of Sciences and Arts, Slovenia

*Correspondence: Anne M. Burrows burrows@duq.edu

Specialty section:

This article was submitted to Behavioral and Evolutionary Ecology,

a section of the journal

Frontiers in Ecology and Evolution

Received: 15 June 2017

Accepted: 27 July 2017

Published: 11 August 2017

Citation:

Burrows AM (2017) Book Review: Evolution Driven by Organismal Behavior: A Unifying View of Life,

Function, Form, Mismatches and Trends. Front. Ecol. Evol. 5:94. doi: 10.3389/fevo.2017.00094
This book presents a new, unifying view of evolution called ONCE (Organic Nonoptimal Constrained Evolution) that is a synthesis of previous theories of evolution coupled with case studies to derive a unique, behavioral-oriented viewpoint on the mechanisms of evolution. The author, Rui Diogo, Ph.D., Howard University College of Medicine, presents a detailed background of the history of evolutionary thought from Aristotle to Evo-Devo as a backdrop to his development of ONCE. The author presents an integrated picture of the origins of evolutionary theory, how it has progressed over time, and provides context for how he has developed ONCE, an integrative and unifying viewpoint about evolution that focuses on behavior of the individual organism, as opposed to a gene-based model, as a driving mechanism to evolution. This book would be useful for graduate students in the biological sciences and history and philosophy of science.

Dr. Diogo's main, over-arching theme in this book is pointing out the active role of individual organisms, be they bacteria, plants, or animals, in the process of evolution by emphasizing the role of the individual's own behavioral choices. The author contrasts this view, the basis of ONCE, with the main tenets of gene-centered Neo-Darwinism and uses multiple case studies of how organisms are active drivers of their own evolution. This book presents a view of evolution that combines Lamarck, Aristotle, Darwin, and modern ideas derived from evo-devo and the author develops arguments on the weaknesses of traditional Neo-Darwinistic conception of evolution by natural selection.

Chapters 1 (Introduction) and 2 (Baldwin's organic selection and the increasing awareness of the evolutionary importance of behavioral shifts) lay the groundwork for how ONCE was developed with a great deal of space devoted to reviewing the work from numerous previous authors and using that work as a basis for the development of ONCE. The author goes to great pains to demonstrate the impact that individuals' behavioral choices play in evolution relative to the Neo-Darwinistic focus on genes.

The author uses Chapters 3 (Behavioral choices and shifts, niche construction, natural selection, extinctions, and asymmetry) and 4 (Evolutionary trends, sexual selection, gene loss, mass extinctions, "progress", and behavioral versus ecological inheritance and novelties versus stability) to further develop the importance of epigenetics, internal and external factors, and the importance of randomness in evolution. Dr. Diogo uses multiple examples from a wide phylogenetic range 
to illustrate the important role that these factors play in evolution and places these factors in the holistic framework of ONCE. I would have liked the author to discuss punctuated equilibrium throughout these two chapters. He describes how rapid evolution can potentially be explained under the auspices of ONCE and it would have been useful to have a comparison with punctuated equilibrium theory here. In discussing the pros and cons of ONCE versus Neo-Darwinism, a table laying out the arguments would have also been useful in helping the reader compare the two systems.

Chapter 5 (Behavioral leads in evolution: exaptations, human evolution, Lamarck, the Cuvier-Geoffroy debate, and form versus function) presents the dilemma of the form-function debate- "does innovative form evolve before innovative behavior or vice versa?", framing it against a historical backdrop. This chapter is a useful lesson in the history and philosophy of evolutionary thought, starting with Aristotle and bringing in modern evo-devo evidence. The author uses the example of the evolution of bird wings and flight in order to illustrate the formfunction debate and ultimately showing how ONCE can explain that behavioral choices (function) can occur prior to the change in the actual form. The inclusion of Figures 5.2 and 5.3 are particularly helpful in illustrating the author's point. The author moves through how sexual selection can be explained using the theoretical construct of ONCE.

Chapters 6 (Eco-morphological mismatches, human "exceptionalism", hybridization, trade-offs, and non-optimality) and 7 (Internal selection, constraints, contingency, homology, reversions, atavisms, von Baer, Haeckel, and Alberch) describe eco-morphological mismatches and how ONCE can be used, rather than Neo-Darwinism, to explain these phenomena and how evolutionary constraints (internal forces) work with external forces in ONCE to influence evolution. The author brings in an enormous volume of previous work to back up his statements and many of these works are included in boxes along with definitions of concepts. Much of the material in these two chapters concerns humans and fossil humans, which is of interest to many anthropologists, paleontologists, and anatomists. These sections are illustrated with examples from the paleontological record.

Chapter 8 (ONCE links internal factors, epigenetics, Matsuda, Waddington, Goldschmidt, and macroevolution) links epigenetics and the behavior of the individual along with the impact of randomness to demonstrate that evolution is not explained solely by genes or by genes and the environment.
There are some excellent figures and tables in this chapter that help the reader focus on the author's main points of how important random factors are in evolution. Some of the figures are very small, though, and would have been improved if they had stretched across two pages in some cases.

Chapter 9 (ONCE ideas are put together: evolutionary behavioral ecology, adaptationism, systems biology, and interdisciplinary) is where the author links all of the previous topics together to form the multidisciplinary, holistic vision of ONCE. Dr. Diogo is remarkably well versed in the evolutionary writings stretching back to Aristotle and he uses this knowledge to form the basis for his theory that organisms and their behavioral choices are the main drivers in evolution. This chapter is densely packed with a lot of information and a flow chart linking these ideas to the formation of ONCE would be helpful for the reader. Otherwise, this chapter is a remarkable synthesis of a wide body of literature.

Chapter 10 (General remarks) provides a final summary and set of general remarks that the author uses to formulate his "take home message" from this book. There are 11 points in this chapter that the author brings to the forefront and provides a relatively succinct summary of each of these points. Given the wealth of information held within this book, a summary like this is a good idea.

The discussion of new ideas is one of the primary ways that science advances. "Evolution Driven by Organismal Behavior" presents a potential new way to conceptualize evolution and brings behavioral choices to the table for deliberation. The author brings in case studies from numerous, diverse fields that provide a reader with much to consider in assessing ONCE.

\section{AUTHOR CONTRIBUTIONS}

The author confirms being the sole contributor of this work and approved it for publication.

Conflict of Interest Statement: The author declares that the research was conducted in the absence of any commercial or financial relationships that could be construed as a potential conflict of interest.

Copyright (C) 2017 Burrows. This is an open-access article distributed under the terms of the Creative Commons Attribution License (CC BY). The use, distribution or reproduction in other forums is permitted, provided the original author (s) or licensor are credited and that the original publication in this journal is cited, in accordance with accepted academic practice. No use, distribution or reproduction is permitted which does not comply with these terms. 